\title{
Causes of Infertility amongst Couples Visited at Infertility Centre
}

\section{Kathmandu, Nepal}

\section{*Pratima Neupane ${ }^{1}$, Deepak Sharma ${ }^{2}$, Prem Prasad Panta ${ }^{3}$, Bijay Aryal ${ }^{4}$, Tarun Poudel ${ }^{5}$,} Kapil Amgain ${ }^{6}$

${ }^{1}$ Lecturer, Department of Community Medicine, Karnali Academy of Health Sciences (KAHS)

${ }^{2}$ Head of Department of Physiology \& Biophysics, KAHS

${ }^{3}$ Associate Professor of Biostatistics, School of Medicine, KAHS

${ }^{4}$ Professor, Department of Pharmacology, KAHS

${ }^{5}$ Professor, General Practice \& Emergency Medicine, School of Medicine, KAHS

${ }^{6}$ Assistant Professor, Head of Department of Clinical Anatomy \& Cell Biology, KAHS

\section{ABSTRACT}

Introduction: Infertility is being a common global problem affecting one couple in six. The purpose of the study was to explore the causes of infertility among couples who visited the infertility centre.

Methodology: Hospital-based descriptive cross-sectional study had been carried out in infertility centre Kathmandu Nepal. One hundred and sixty-five married couple with infertility problem availing the infertility treatment was selected on first come first serve basic sampling method from the infertility treatment centre.

Result: The infertility problem varied with the age. The problem was highest among the females of age group 26-30 years (51\%), similarly, in males, it was predominant at the age of $31-35$ years (45\%). The most common causes of female infertility were ovarian cyst (37\%) and heavy bleeding (18.7\%), uterine fibroids (9\%), Pelvic inflammation (9\%), Thyroid disease $(21.8 \%)$, whereas in males the infertility was mostly due to Oligospermia (17.5\%), Azoospermia (5.5\%), Hydrocele (7.8), Mumps orchids $(6 \%)$.

Conclusion: Infertility was due to various causes in the male or/and the female partner, however, infertility among couples were mostly due to the problem in females. Infertility is a complex problem that should be considered carefully by the individual, community peoples, government and stakeholders in each country.

Keywords: Male Fertility, Female Fertility, Causes, Couple, Infertility, Ovarian Cyst

\section{*Corresponding Author:}

\section{Ms. Pratima Neupane}

Email: pratimaneupane07@gmail.com

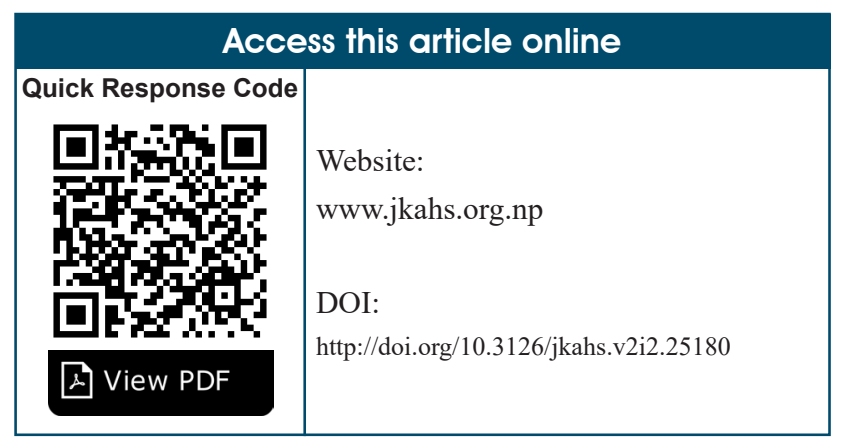

\section{Article Info.}

\section{How to cite this article?}

Neupane P, Sharma D, Panta PP, Aryal B, Poudel T, Kapil Amgain Causes of Infertility amongst Couples Visited at Infertility Centre Kathmandu, Nepal. Journal of Karnali Academy of Health Sciences. 2019;2(2):133-137

Received: 28 April, Accepted: 2 June, Published: 30 August 2019

Conflict of Interest: None, Source of Support: None 


\section{BACKGROUND}

The problem of infertility has not given due attention because it is not a life-threatening condition with invisible losses, and it consequences are manifold. The prevalence of infertility is varies worldwide ranging from $3 \%$ to $7 \%$, majority being residents of developing countries ${ }^{2}$. Infertility is being a common global problem affecting one couple in six. ${ }^{3}$ Approximately 167 million ever married woman aged 15-49 years in developing countries were infertile ${ }^{4}$. The evidence for changes in the prevalence of infertility is difficult to establish ${ }^{5}$. Infertility is defined as the inability of getting pregnant after trying for at least 6 months or one year, for women over 35 years old, without use of birth control means and while having normal sexual intercourse. Assisted reproduction includes all the methods used for fertilization, which is not achieved through sexual intercourse 6 overall primary and secondary infertility in South Asia, on the basis of women at the end of their reproductive lives in the age group 45-49 years, suggests an infertility rate of approximately $10 \%, 8 \%$ in India, $10 \%$ in Pakistan, $11 \%$ in Sri Lanka, $12 \%$ in Nepal and $15 \%$ in Bangladesh. ${ }^{7}$ In Nepal infertility problems were from the district Kapilvastu (14.9\%) and Rautahat $(8.1 \%)$. Maximum number $(36 \%)$ of women with infertility fell in the age group of 15- 19 years. ${ }^{8}$

Problem of infertility is a rising issue in Nepal and it needs to be exposed. The problem of infertility has not given attention considering the fact that it is not the life threatening, but, it has substantial community health problems such as depression, anxiety domestic violence and social isolation. Despite the fact, so far there has been no effective program implemented in Nepal to address to minimize the various causes of the infertility. So we aim to explore the relevant factors causing infertility among couples who visited the infertility centre. We expect that the study will identify the leading cause of infertility in Nepal, and would help to substantially decrease the burden in the community.

\section{METHOD}

Hospital based Descriptive cross sectional study had been carried out in infertility centre Kathmandu Nepal. One sixty five married couple with infertility problem availing the infertility treatment was selected on first come first serve basic sampling method from infertility treatment centre. Duration of study period was six month, February 2017 to August 2017. Before conducting research, approval was taken from hospital administration as well as from doctor. Verbal Informed Consent was taken from each respondent before collecting the information. Data were collected by interview technique using pre-structured questionnaire, and case histories were collected from the medical record of the patients. Collected data were analysed in SPSS version 16.0.

\section{RESULT}

Age wise distribution of infertile couples was shown in table 1 and 2 . The infertility problem varied with the age. The problem was highest (51\%) among the females of age group 26-30 years, but the infertility problem was absent in among the females of the age group 41-45 years. Similarly in males it was predominant (45\%) at the age of 31-35 years where as the problem was absent among the males at the age group 21-25 years. This table described that the age was one of the important cause of infertility among infertile couples.

\section{Table 1: Age and sex-wise distribution of infertility}

\begin{tabular}{ccc}
\hline \multirow{2}{*}{$\begin{array}{c}\text { Age group } \\
\text { of the }\end{array}$} & $\begin{array}{c}\text { Frequency distribution of couples } \\
\text { (\%) Couples }\end{array}$ \\
\cline { 2 - 3 } & Female & Male \\
\hline $21-25$ & $29(17.57)$ & - \\
$26-30$ & $85(51.52)$ & $31(18.78)$ \\
$31-35$ & $37(22-43)$ & $74(44.85)$ \\
$36-40$ & $14(8.48)$ & $45(27.28)$ \\
$41-45$ & - & $15(9.09)$ \\
\hline
\end{tabular}


Causes of infertility in couples are shown in table 3 and 4 . The most common cause of female infertility was ovarian cyst (37\%), heavy bleeding (15.7\%), Pelvic inflammatory Disease (9.69\%), Uterine fibroids (9.09\%), Ectopic pregnancy $(6.66 \%)$ and Thyroid disease $(21.81 \%)$. This study showed that reproductive problem and the thyroid disease are the main causes of infertility in female couples. whereas in males the infertility problem were mostly due to Oligospermia (17.5\%), Azoospermia (5.5\%), Hydrocele (7.87\%), Mumps associated with Orchitis (6.06\%), Testicular Torsion (2.42\%) and Epididymitis $(0.6 \%)$.

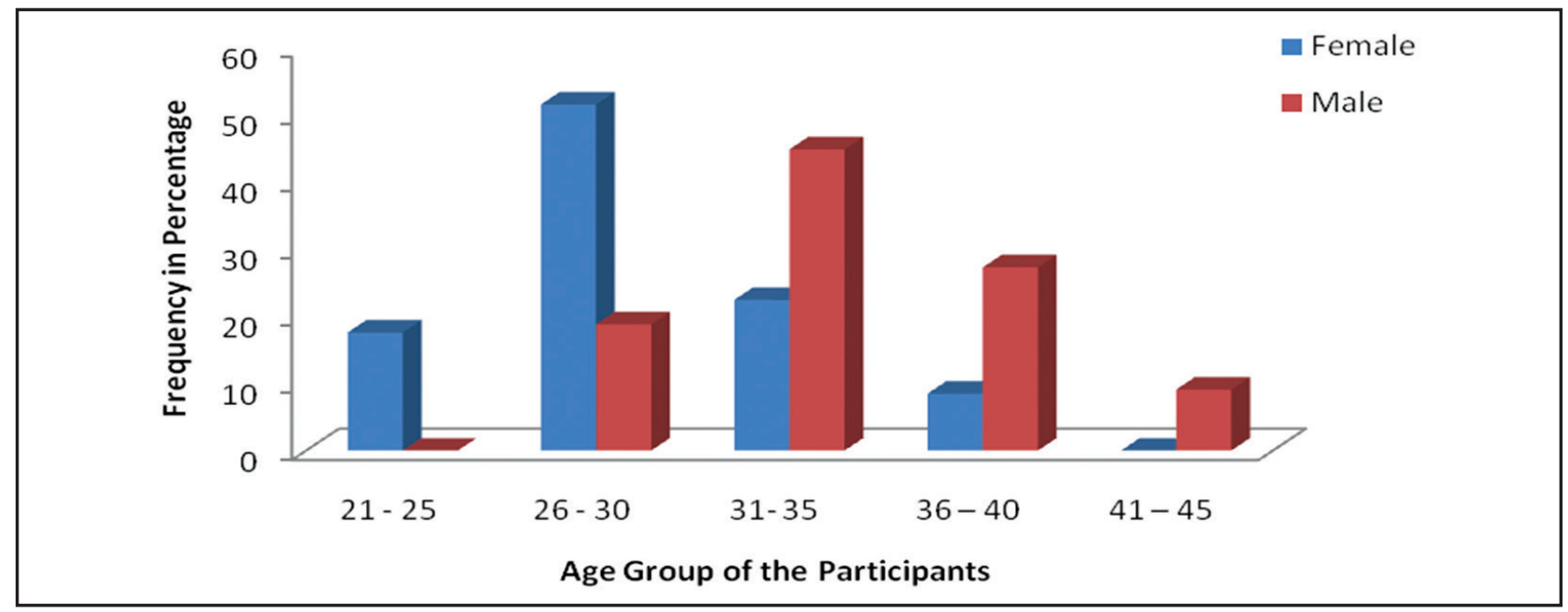

Figure 1: Age and sex-wise distribution of Infertility in couples

Table 2: Causes of infertility in female

\begin{tabular}{lcc}
\hline \multicolumn{1}{c}{ Types of problem } & Frequency & Percentage \\
\hline Ovarian Cyst & 61 & 37.00 \\
Thyroid disease & 36 & 21.81 \\
Heavy Bleeding (Polymenorrhoea) & 26 & 15.75 \\
Pelvic inflammatory Disease (PID) & 16 & 09.69 \\
Uterine fibroids & 15 & 09.09 \\
Ectopic pregnancy & 11 & 06.66 \\
\hline
\end{tabular}
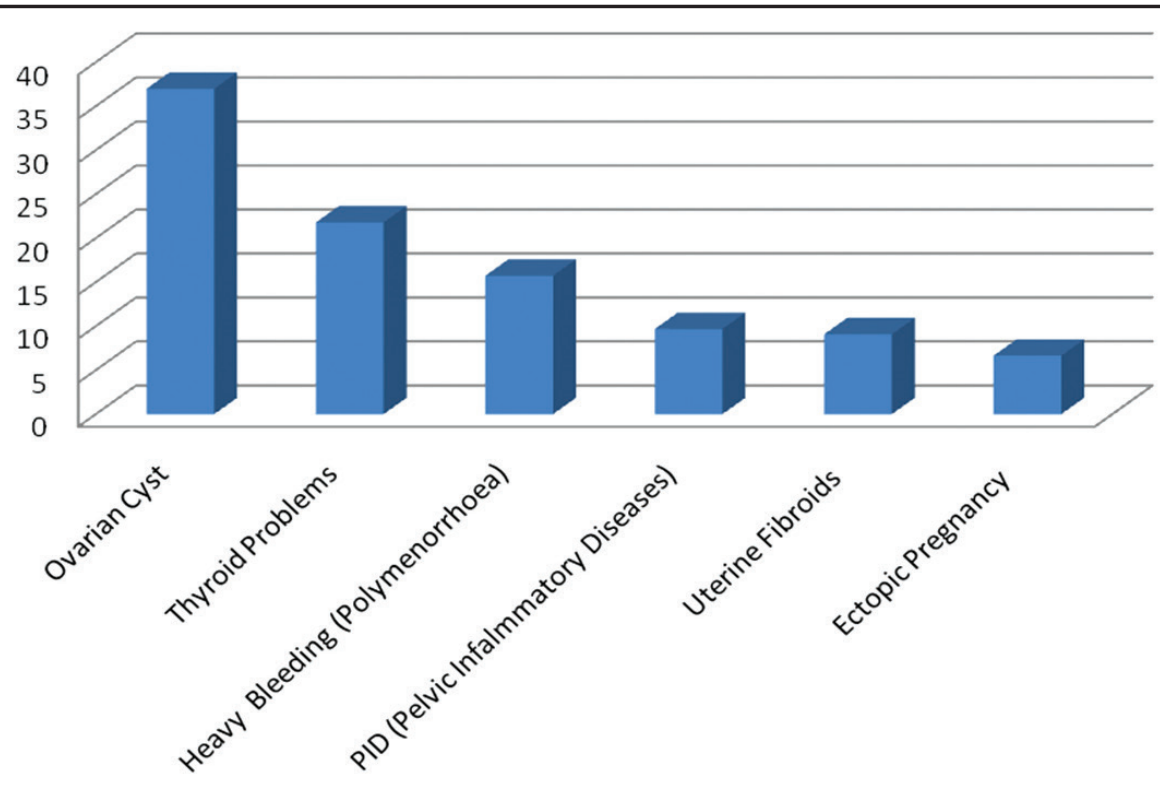

Figure 2: Causes of Female Infertility 
Table 3: Causes of infertility in male

\begin{tabular}{lcc}
\hline \multicolumn{1}{c}{ Types of disease } & Frequency & Percentage \\
\hline Mumps associated & 10 & 6.06 \\
with Orchitis & 13 & 7.87 \\
Hydrocele & 29 & 17.57 \\
Oligospermia & 09 & 5.45 \\
Azoospermia & 01 & 0.60 \\
Epididymitis & 04 & 2.42 \\
Testicular Torsion & &
\end{tabular}

\section{DISCUSSION}

The present study showed that the higher proportion of infertile males were of age group 31-35 years, while higher proportion of infertile females were of age 26-30 years. These findings are supported by a Reproductive morbidity report on clinical based survey in Nepal. One third of the infertile couples in the study population were in their late thirty's. ${ }^{5-8}$ The study further stated, the infertility problems grows more with increasing age, peak rate of conception occurs at the age of 24 years for both men and women and declines considerably after the age of 35 years. ${ }^{6-8,11}$ The other studies have also revealed that the age group of 20-29 years as the most vulnerable age group for female infertility, and more than half of the total infertility problems in these studies were in this age group, accounting for more than half of the study population..$^{9-12}$

This study demonstrated abnormal semen quality (oligospermia and azospermia) in male partners, as the predominant causes for their inability to conceive. Our findings was greatly supported by the studies conducted in Nigeria, which showed oligspermia (25.6\%), azospermia (6.2\%), asthenozoospermia $(11.5 \%)$ were the major causes of infertility in Nigerian couples. ${ }^{13-15}$ There was also a regional variation in the prevalence of oligozoospermia and azoospermia in male partners of infertile couples. ${ }^{16}$, ${ }^{17}$ The similar causes of infertility in males were also identified among Indian couples, and the problem was widely present at 35-40 years of age, the same age group that is mostly affected in our study population. ${ }^{17}$
This study showed, the reproductive problems were the major cause for female infertility followed by thyroid problems. Considering all the reproductive disorders, a high proportion of infertile females had ovarian cyst in our study population. Another study also had shown the occurrence of ovarian cyst to be high at the reproductive age. ${ }^{18}$ One woman out of seven in France will consult a doctor for an infertility problem during her reproductive life. The main causes of female infertility were ovulation disorders (32\%) and $(26 \%)$ tubal damage. ${ }^{19}$

\section{CONCLUSION}

Infertility was due to various causes in the male or/ and the female partner, however, the infertility among couples were mostly due to the problem in females. Occurrence of infertility is maximum during late twenty's in female and early thirty's in male. Major cause for infertility is ovarian cyst, thyroid disorder, PID, uterine fibroids, and ectopic pregnancy in females where as abnormal sperm quality, hydrocele, and history of mumps in males. Further study should be done in the couples of reproductive age group to identify the real cause of infertility prevailing amongst the couples of reproductive age group.

\section{ACKNOWLEDGEMENT}

I acknowledge and thank infertility centre and Dr. Uma Shrivastava for her advice and support during this study.

\section{REFERENCES}

1. Sharmistha D. Infertility rises at alarming pace in India. English.news.cn. 07-16 2010; 15:04:38.

2. Tripathi N. Infertility among Indian Women: Emerging Evidence and Need for Policy Measures. International Institute for Population Sciences. 2011

3. Nachtigall RD. International disparities in access infertility services. Fertil Steril. 2006: 85, 871-5. 
4. Rutstein SO, Shah IH. Infecundity infertility, and childlessness in developing countries. DHS comparative reports, Calverton, MD, ORC Macro and the world health Organization. 2004.

5. Ashraf D, Ali D. Epidemiology of Female Infertility. Biosciences Biotechnology Research Asia. 2013; 10 (2): 559-567.

6. Ombelet W, Cooke I, Dyer S, Serour G, Devroey P. Infertility and the provision of infertility medical services in developing countries. Hum Reprod Update. 2008; 14(6): 605-21.

7. Menken J, Trussell J, Larsen U. Age and infertility Science. American Association for the Advancement of Science.1986; 233(4771):1389-1394.

8. Status of Reproductive Morbidities in Nepal. A reproductive morbidity report on clinic based survey. UNFPA. 2006.

9. Brugo-Olmedo S, Chillik C, Kopelman S. Definition and causes of infertility. Reprod Biomed Online. 2001; 2(1):41-53.

10. Kelly-Weeder S, Cox CL. The impact of lifestyle risk factors on female infertility. Women Health. 2006; 44(4):1-23.

11. Roupa Z, Polikandrioti M, Sotiropoulou P, Faros E, Koulouri A, Wozniak G,Gourni M. Causes of infertility in women at reproductive age. Health science journal. 2009; 3(2):80-87.

12. Baird DT, Collins J, Eqozcue J, Evers LH, Gianaroli L, Leridon H, et al. Fertility and ageing. Hum Reprod Update. 2005; 11(3):261-76.
13. Adeniji RA, Olayemi O, Okunlola MA, Aimakhu CO. Pattern of semen analysis of male partners of infertile couples at the University College Hospital, lbadan. West Afr J Med 2003; 22:243-5.

14. Ugwuja EI, Ugwu NC, Ejikeme BN. Prevalence of low sperm count and abnormal semen parameters in male partners of women consulting at infertility clinic in Abakaliki, Nigeria. Afr J Reprod Health 2008; 12:67-73

15. Ikechebelu JI, Adinma JI, Orie EF, Ikegwuonu SO. High prevalence of male infertility in Southeastern Nigeria. J Obstet Gynaecol 2003; 23:657-9.

16. Mehta RH, Makwana S, Ranga GM, Srinivasan RJ, Virk SS. Prevalences of oligozoospermia and azoospermia in male partners of infertile couples from different parts of India. Asian J Androl 2006; 8:89-93.

17. Mital P, Jain S, Jain D, Patel B, Phanse N, Vyas P, Rathore P. Prevalence of Different Factors Responsible for Infertility. Research Journal of Recent Sciences 2012; 1(11):207-211.

18. ACOG Practice Bulletin. Management of adnexal masses. Obstetrics and Gynecology 2007; 110, 201-214.

19. Thonneau1 P, Marchand S, Tallec A, Ferial $\mathrm{M}-\mathrm{L}$, Ducot B, Lansac $\mathrm{J}$ et al. Incidence and main causes of infertility in a resident population (1 850 000) of three French regions. Human Reproductionhumrep.oxfordjournals. org, Hum. Reprod.1991; 6:811-816. 